\title{
TRANSMISSÃO DE ZIKA VÍRUS DURANTE A GESTAÇÃO EM RECÉM-NASCIDOS E MICROCEFALIA: UMA REVISÃO NARRATIVA
}

\author{
Transmission Of Zika Virus During Pregnancy In Newborn And Microcephaly: A Narrative \\ Review
}

Ana Caroline Nogueira Moreira Souza ${ }^{\underline{l^{*}}}$, Jessyca Zanella Ferreira de Oliveira 2 , Gabriel Spechoto Moreira ${ }^{2}$, Ana Luísa Perillo ${ }^{4}$

\begin{abstract}
RESUMO
O Brasil foi o primeiro país a identificar uma possível relação entre a infecção pelo vírus Zika na gestação e a ocorrência de microcefalia em recém-nascidos (RN). A partir do estabelecimento de uma força tarefa nacional, dentre os primeiros 35 casos de RN com microcefalia notificados em oito estados do país (Agosto e Outubro de 2015), todas as mães residiam ou visitaram áreas infectadas pelo vírus durante a gestação. Esta pesquisa teve por objetivo buscar evidências na literatura, acerca dos achados sobre a relação entre a infecção pelo vírus Zika durante a gestação e as consequências neonatais, por meio de uma revisão narrativa. Para a construção da presente revisão, foi determinado algumas etapas: definição e refinamento do tema de pesquisa; determinação dos critérios de inclusão e exclusão dos artigos pesquisados, discussão dos resultados obtidos e descrição da síntese do conhecimento obtido. As plataformas escolhidas foram: Scielo, PubMed e Web of Science, as palavras-chave utilizadas foram "child" e "Zika Vírus". Como critério de inclusão foram obtidos artigos publicados no período de 2015 a 2020, nos idiomas português e/ou inglês. Foram excluídos artigos publicados fora dos padrões determinados acima. As anomalias no (Sistema Nervoso Central) SNC dos pacientes acometidos com ZV revelam características especificas para crianças, durante o seu desenvolvimento. Estas anomalias podem ser representadas como convulsões, disfagia, irritabilidade, hipertonia, hiperreflexia e reflexos arcaicos aumentados. Apesar de muitos estudos acerca do ZV e a associação da microcefalia, através a transmissão via transplacentária, não é possível confirmar com precisão o desencadeamento por ambos. Ainda não se sabe ao certo o mecanismo que leva ao surgimento da microcefalia por meio da infecção do Zika vírus. O que tudo indica é que a infecção e a inflamação geradas pelo micro-organismo causem danos na estrutura e replicação das células nervosas.

Palavras-chave: Zika Vírus; Microcefalia; gravidez; recém-nascido.
\end{abstract}

\section{ABSTRACT}

Brazil was the first country to identify a possible relationship between Zika virus infection during pregnancy and the occurrence of microcephaly in newborns (NB). After the establishment of a national task force, among the first 35 cases of NB with microcephaly reported in eight states in the country (August and October 2015), all mothers lived in or visited areas infected by the virus during pregnancy. This research aimed to seek evidence in the literature about the findings on the relationship between Zika virus infection during pregnancy and neonatal consequences, through a narrative review. For the construction of this review, some steps were determined: definition and refinement of the research theme; determination of the inclusion and exclusion criteria of the researched articles, discussion of the obtained results and description of the obtained knowledge synthesis. The chosen platforms were: Scielo, PubMed and Web of Science, the keywords used were "child" and "Zika Virus". As inclusion criteria, articles published from 2015 to 2020 were obtained, in Portuguese and/or English. Articles published outside the standards set forth above were excluded. Anomalies in the (Central Nervous System) CNS of patients affected with ZV reveal specific characteristics for children during their development. These anomalies can be represented as seizures, dysphagia, irritability, hypertonia, hyperreflexia and increased archaic reflexes. Despite many studies about ZV and the association of microcephaly, through transplacental transmission, it is not possible to precisely confirm the triggering by both. The mechanism that leads to the emergence of microcephaly through Zika virus infection is not yet known for sure. What everything indicates is that the infection and inflammation generated by the microorganism cause damage to the structure and replication of nerve cells.

Keywords: Zika Virus; Microcephaly; pregnancy; newborn. 1. Especialista na área de Medicina em Saúde da Família, Preceptoria e Clínica Médica, Preceptora do curso de Medicina pela Faculdade Morgana Potrich - FAMP.
Goiânia-GO, Brasil.

2. Acadêmicos de Medicina, Centro Universitário de Mineiros - UNIFIMES, Mineiros-GO, Brasil.

*Autor para Correspondência. E-mail: anacarolinemoreira@ hotmail.com 


\section{INTRODUÇÃO}

Em 2015 ocorreu um surto de Zika vírus (ZV) no Nordeste do Brasil, devido a circulação do seu vetor, Aedes aegypti. Os primeiros relatos entre a microcefalia e Zika vírus foram publicados por pesquisadores brasileiros, onde descreveram o aumento de recém-nascidos com microcefalia em regiões afetadas pelo vírus, comprovado através da presença do RNA do ZV no líquido amniótico. ${ }^{1}$

Apesar do Ministério da Saúde controlar o surto do ZV, a OMS declarou emergência pública internacional. Em 2018 foram registrados diversos casos na Índia, afetando pelo menos 117 pessoas. $^{2}$

Casos de doença $\mathrm{ZV}$ adquirida sexualmente foram relatados e está provado que o vírus pode ser transmitido da mãe para o embrião durante a gravidez ${ }^{3}$. Além do sangue, o vírus pode ser identificado em outros fluidos corporais, como saliva ${ }^{4}$, sêmen ${ }^{5}$, secreções vaginais ${ }^{6}$, líquido amniótico ${ }^{7}$, líquido cefalorraquidiano, lágrimas ${ }^{9}$ e urina de pessoas infectadas ${ }^{10}$. Além disso, o material genético do vírus também foi identificado no leite materno 11 .

O período de incubação de ZV é estimado entre 3 e 14 dias. A maioria das pessoas infectadas permanece assintomática. Parte dos sintomas comuns que ocorrem em pacientes são erupções cutâneas, febre, artrite ou junta pintura, conjuntivite, dor muscular, dores de cabeça, dor retrobulbar, edema e vômito ${ }^{3}$. Um papel principal no diagnóstico de infecção por o vírus é a identificação do RNA viral por meio de RT-PCR e a identificação de anticorpos IgM através do método MAC-ELISA ${ }^{12}$.

A síndrome congênita do $\mathrm{ZV}$ pode apresentar algumas especificidades clinicas como a microcefalia e ruptura do cérebro fetal, desproporção craniofacial, depressão biparietal, occipital proeminente, excesso de pele na nuca, malformações corticais e calcificações cerebrais ${ }^{13}$.
Neste sentido, esta pesquisa teve por objetivo buscar evidências na literatura, acerca dos achados sobre a relação entre a infecção pelo vírus Zika durante a gestação e as consequências neonatais, por meio de uma revisão narrativa.

\section{METODOLOGIA}

Trata-se de um estudo de revisão narrativa, utilizando como estratégia de coleta de dados a sintetização dos resultados de publicações relacionadas com a temática determinada. Para a construção da presente revisão, foi determinado algumas etapas: definição e refinamento do tema de pesquisa; determinação dos critérios de inclusão e exclusão dos artigos pesquisados, discussão dos resultados obtidos e descrição da síntese do conhecimento obtido.

As plataformas escolhidas foram: Scielo, PubMed e Web of Science, as palavras-chave utilizadas foram "child" e "Zika Vírus". Como critério de inclusão foram obtidos artigos publicados no período de 2015 a 2020, nos idiomas português e/ou inglês. Foram excluídos artigos publicados fora dos padrões determinados acima.

\section{REVISÃO}

O primeiro caso de vírus Zika foi identificado em humanos em 1952(1) e descrito até o ano de 2007 como causador de infecções esporádicas em humanos na África e na Ásia. Em 2007, foi relatado um surto a partir dos Estados Federados da Micronésia, correspondendo ao primeiro diagnóstico por vírus Zika para além da África e Ásia. Desde então, a infeção se espalhou para outras ilhas do Pacífico, atingindo, posteriormente, o Brasil e a Colômbia ${ }^{2}$.

O Brasil foi o primeiro país a identificar uma possível relação entre a infecção pelo vírus Zika na 
gestação e a ocorrência de microcefalia em recémnascidos (RN). A partir do estabelecimento de uma força tarefa nacional, dentre os primeiros 35 casos de $\mathrm{RN}$ com microcefalia notificados em oito estados do país (Agosto e Outubro de 2015), todas as mães residiam ou visitaram áreas infectadas pelo vírus durante a gestação. ${ }^{2}$

As anomalias no (Sistema Nervoso Central) SNC dos pacientes acometidos com ZV revelam características especificas para crianças, durante o seu desenvolvimento. Estas anomalias podem ser representadas como convulsões, disfagia, irritabilidade, hipertonia, hiperreflexia e reflexos arcaicos aumentados. ${ }^{11}$

Outras anomalias também foram descritas na literatura, como hiperreflexia, hipertonia, desenvolvimento atípico e deficit na função manual, mas a visão e a deglutição não seguiram os mesmos padrões, sugerindo associação às alterações encefálicas. Além disso, pode ocorrer convulsões não febris, indicando distúrbio convulsivo, hospitalização por bronquite e pneumonia, dificuldades para dormir, comer ou engolir, comprometimento motor grave compatível com paralisia cerebral, resposta prejudicada a estímulos auditivos, anormalidades na retina e resposta prejudicada a estímulos visuais. ${ }^{13}$

A contaminação de crianças que foram expostas ao ZV ainda intraútero, tem a oportunidade de acompanhamento do desenvolvimento neurológico, podendo observar o atraso neste processo, levando a considerar que as avaliações necessitam ser precoces e detalhadas para a detecção de problemas neurodesenvolvimentais. ${ }^{14}$

Estudos realizados a partir do acompanhamento de crianças que necessitaram de internações até os dois anos de idade, constatou os motivos das hospitalizações, sendo eles epilepsia não controlada, derivação ventriculoperitoneal, infecção, diarreia, infecção do trato urinário e pneumonia, bem como episódios recorrentes de convulsão e uso de medicamentos antiepiléticos. Já o acompanhamento e avaliação neurológica de crianças entre três e quatro meses de idade mostrou desempenho atípico, com tônus muscular, motricidade, sucção, deglutição e respiração alterados. ${ }^{11}$

Outras características foram descritas como casos de bebês que apresentaram pé torto, artrogripose e fenda palatina. Crianças entre 18 e 24 meses de idade apresentaram comprometimento do desenvolvimento neuropsicomotor, com repercussões na deambulação e linguagem. ${ }^{11}$

Além da transmissão do ZV via transplacentária, estudos realizados no Laboratório de Biologia Molecular de Flavivírus do Instituto Oswaldo Cruz analisou amostras de saliva e urina de dois pacientes, coletadas durante a apresentação de sintomas compatíveis com o vírus Zika. A presença do material genético do vírus Zika foi confirmada pela técnica de RT-PCR em tempo real, no entanto, tais achados não comprovam a possibilidade de infecção de outras pessoas de maneira sistêmica através desses fluidos. ${ }^{16}$

Há relatos de infecção por via sexual em um estudo realizado nos Estados Unidos da América, onde o vírus foi isolado do sêmen de um paciente. ${ }^{17,18}$ Apesar destes relatos, apenas $18 \%$ das infecções humanas pelo vírus Zika resultam em manifestações clínicas. ${ }^{19}$

Por determinação da Organização Mundial de Saúde e com o objetivo de qualificar a vigilância da microcefalia relacionada à infecção pelo $\mathrm{ZV}$, foi estabelecido critérios critérios para identificação dos casos: "1. Gestante com possível infecção pelo vírus Zika; 2. Feto com alterações do SNC possivelmente relacionadas à infecção pelo vírus Zika; 3. Aborto espontâneo decorrente de possível associação com infecção pelo vírus Zika; 4. Natimorto decorrente de 
possível infecção pelo vírus Zika; 5. Recém-nascido vivo com microcefalia possivelmente associada à infecção pelo vírus Zika"(pg.22). ${ }^{20}$

\section{CONCLUSÃO}

Apesar de muitos estudos acerca do $\mathrm{ZV}$ e a associação da microcefalia, através a transmissão via transplacentária, não é possível confirmar com precisão o desencadeamento por ambos.

Ainda não se sabe ao certo o mecanismo que leva ao surgimento da microcefalia por meio da infecção do Zika vírus. O que tudo indica é que a infecção e a inflamação geradas pelo micro-organismo causem danos na estrutura e replicação das células nervosas.

\section{REFERÊNCIAS BIBLIOGRÁFICAS}

1. Dick GW, Kitchen SF, Haddow AJ. Zika virus. I. Isolations and serological specificity. Trans R Soc Trop Med Hyg

[Internet]. 1952 [acesso em: 31 mar. 2016];46(5):509-20. Disponivel em: http://dx.doi.org/10.1016/0035-

9203(52)90042-4.

2. World Health Organization. Zika virus outbreaks in the Americas. Wkly Epidemiol Rec [Internet]. 2015 [acesso em: 31 mar. 2016];90(45):609-10. Disponível em: http://www.who.int/wer/2015/wer9045.pdf?ua=1.

3. L.R. Peterson, D.J. Jamieson, A.M. Powers, M.A. Honein, Zika virus (NEJM), N. Engl. J. Med. (2016).

4. L. Barzon, M. Pacenti, A. Berto, A. Sinigaglia, E. Franchin, E. Lavezzo, P. Brugnaro,

G. Palù, Isolation of infectious Zika virus from saliva and prolonged viral RNA

shedding in a traveller returning from the Dominican Republic to Italy, January

2016, Eurosurveillance. https://doi.org/10.2807/15607917.es.2016.21.10.301

59, 2016.
5. B. Atkinson, P. Hearn, B. Afrough, S. Lumley, D. Carter, E.J. Aarons, A.J. Simpson,

T.J. Brooks, R. Hewson, Detection of zika virus in semen, Emerg. Infect. Dis.

(2016), https://doi.org/10.3201/eid2205.160107

6. N. Prisant, L. Bujan, H. Benichou, P.H. Hayot, L. Pavili, S. Lurel, C. Herrmann,

E. Janky, G. Joguet, Zika virus in the female genital tract, Lancet Infect. Dis.

(2016), https://doi.org/10.1016/S1473-3099(16)30193-1.

7. G. Calvet, R.S. Aguiar, A.S.O. Melo, S.A. et al. Tanuri, A.M.B. de Filippis, Detection and sequencing of Zika virus from amniotic fluid of fetuses with microcephaly in Brazil: a case study, Lancet Infect. Dis. (2016), https://doi.org/10.1016/S1473-3099(16)00095-5.

8. D .M. Salgado, R. Vega, J.A. Rodríguez, A. ' Nino, R. Rodríguez, A. ' Ortiz, I. DeLaura, I. Bosch, C.F. Narv'aez, Clinical, laboratory and immune aspects of Zika virusassociated encephalitis in children, Int. J. Infect. Dis. (2020), https://doi.org/ 10.1016/j.ijid.2019.10.030.

9. . Sun, D. Wu, H. Zhong, D. Guan, H. Zhang, Q. Tan, C. $\mathrm{Ke}$, Presence of Zika virus in conjunctival fluid, JAMA Ophthalmol (2016), https://doi.org/10.1001/jamaophthalmol.2016.3417.

10. A.C. Gourinat, O. O'Connor, E. Calvez, C. Goarant, M. Dupont-Rouzeyrol,

Detection of zika virus in urine, Emerg. Infect. Dis. (2015), https://doi.org/ 10.3201/eid2101.140894.

11. S. Colt, M.N. Garcia-Casal, J.P. Pena-Rosas, J.L. Finkelstein, P. Rayco-Solon, Z.

C. Weise Prinzo, S. Mehta, Transmission of Zika virus through breast milk and other breastfeeding-related bodily-fluids: a systematic review, PLoS Neglected

Trop. Dis. (2017), https://doi.org/10.1371/journal.pntd.0005528.

12. R.S. Lanciotti, O.L. Kosoy, J.J. Laven, J.O. Velez, A.J. Lambert, A.J. Johnson, S. 
M. Stanfield, M.R. Duffy, Genetic and serologic properties of Zika virus associated with an epidemic, Yap State, Micronesia, Emerg. Infect. Dis. (2007), https://doi. org/10.3201/eid1408.080287, 2008.

13. Silva AA, Ganz JS, Sousa PD, Doriqui MJ, Ribeiro MR, Branco MD, et al. Early growth and neurologic outcomes of infants with probable congenital Zika vírus syndrome.

Emerg Infect Dis. 2016;22:1953-6. https://doi.org/10.3201/eid2211.160956

14. Schuler-Faccini L, Ribeiro EM, Ian ML, et al. Possible Association Between Zika Virus Infection and Microcephaly - Brazil, 2015. CDC [periodico online]. 2016; vol.65, n. 3. pp. 59-62

15. Chang Y, Jiang Y, Li C, et al. Different Gene Networks are Disturbed by Zika Virus Infection in a Mouse Microcephaly Model. Genomics, Proteomics \& Bioinformatics. 2019.

16. Fundação Oswaldo Cruz. Fiocruz detecta presença de vírus zika com potencial de infecção em saliva e urina [Internet]. Rio de Janeiro: FIOCRUZ; 2016. Disponível em: http://portal.fiocruz.br/pt-br/content/fiocruz-detectaprensenca-de-viruz-zika-com-potencial-de-infeccao-emsaliva-e-urina

17. McCarthy M. Zika virus was transmitted by sexual contact in Texas, health officials report. BMJ [Internet]. 2016. Disponível em: http://dx.doi.org/10.1136/bmj.i720

18. Musso D, Roche C, Robin E, Nhan T, Teissier A, CaoLormeau VM. Potential sexual transmission of Zika virus. Emerg Infect Dis [Internet]. 2015. Disponível em: http://dx.doi.org/10.3201/eid2102.141363

19. Musso D, Roche C, Robin E, Nhan T, Teissier A, CaoLormeau VM. Potential sexual transmission of Zika virus. Emerg Infect Dis [Internet]. 2015.Disponível em: http://dx.doi.org/10.3201/eid2102.141363

20. Ministério da Saúde. Protocolo de atenção à saúde e resposta à ocorrência de microcefalia relacionada à infecção pelo vírus Zika [Internet]. Brasília: Ministério da Saúde; 2016.

http://www.saude.go.gov.br/public/media/ZgUINSpZiwmbr 3/64622069021204406934.pdf 